University of Nebraska - Lincoln

DigitalCommons@University of Nebraska - Lincoln

Marjorie A. Langell Publications

Published Research - Department of Chemistry

May 1997

\title{
Thermal decomposition reactions of acetaldehyde and acetone on $\mathrm{Si}(100)$
}

J.L. Armstrong

University of Texas at Austin, Austin, Texas

J.M. White

University of Texas at Austin, Austin, Texas

Marjorie Langell

University of Nebraska - Lincoln, mlangell1@unl.edu

Follow this and additional works at: https://digitalcommons.unl.edu/chemistrylangell

Part of the Chemistry Commons

Armstrong, J.L.; White, J.M.; and Langell, Marjorie , "Thermal decomposition reactions of acetaldehyde and acetone on Si(100)" (1997). Marjorie A. Langell Publications. 6.

https://digitalcommons.unl.edu/chemistrylangell/6

This Article is brought to you for free and open access by the Published Research - Department of Chemistry at DigitalCommons@University of Nebraska - Lincoln. It has been accepted for inclusion in Marjorie A. Langell Publications by an authorized administrator of DigitalCommons@University of Nebraska - Lincoln. 


\title{
Thermal decomposition reactions of acetaldehyde and acetone on $\mathrm{Si}(100)$
}

\author{
J. L. Armstrong and J. M. White ${ }^{\text {a) }}$ \\ Department of Chemistry and Biochemistry, University of Texas at Austin, Austin, Texas 78712 \\ M. Langell \\ Department of Chemistry, University of Nebraska, Lincoln, Nebraska 68588
}

(Received 1 October 1996; accepted 11 March 1997)

\begin{abstract}
We have studied the thermal interactions of acetone and acetaldehyde on $\mathrm{Si}(100)$, both sputtered and annealed, using high resolution electron energy loss spectroscopy, (HREELS), x-ray photoelectron spectroscopy (XPS), and temperature programmed desorption (TPD). There is no carbonyl stretch in HREELS and the $\mathrm{C}$ and $\mathrm{O}(1 s)$ XPS peaks reflect two different carbonyl processes, one involving bond cleavage, the other a reduction of the $\mathrm{C}-\mathrm{O}$ bond order. Hydrogen TPD gives a peak at $840-850 \mathrm{~K}$ which is as much as threefold more intense than from $\mathrm{H}$-saturated $\mathrm{Si}(100)$. SiO desorbs near $1050 \mathrm{~K}$ and XPS shows total loss of oxygen and retention of carbon. Approximately $34 \%$ of the acetaldehyde monolayer and $62 \%$ of the acetone monolayer decomposes on annealed $\mathrm{Si}(100)$ to produce silicon carbide. In contrast, after sputtering with $500 \mathrm{eV}$ Ar ions, these percentages are reduced to $14 \%$ and $25 \%$, respectively. We conclude that Si dimers play an important role in the chemistry of carbonyl groups. (C) 1997 American Vacuum Society. [S0734-2101(97)58303-5]
\end{abstract}

\section{INTRODUCTION}

The chemistry of small organic molecules on $\mathrm{Si}(100)$ is of interest from both fundamental and technological perspectives. Simple hydrocarbons are possible sources for making $\mathrm{SiC}$ and for growing thin diamond films. ${ }^{1-4}$ Acetone has been proposed, and studied, as a potential source of methyl radicals (produced by photodissociation) which may be used to form thin diamond films on silicon. ${ }^{5}$ There has also been interest in using carbonyl functional groups to chelate metals; the chelated metals are then either delivered to or removed from a Si or oxide surface, e.g., copper (II) bis(acetylacetonate) $\left[\mathrm{Cu}(a c a c)_{2}\right]$ and copper (II) bis $(1,1,1,5,5,5-$ hexafluoropentanedionate) $\left[\mathrm{Cu}(u f a c)_{2}\right] .{ }^{6-15}$

Scientifically, $\operatorname{Si}(100)$ is interesting because of the chemistry produced by the structure of the surface atoms. Clean $\mathrm{Si}(100)$ surfaces reconstruct to form dimer pairs $(2 \times 1)$ which stabilize the surface. ${ }^{16,17}$ These dimer structures often play important roles in determining the way an adsorbate binds and reacts.

Carbon monoxide, which bears some relation to acetone and acetaldehyde, does not adsorb on $\mathrm{Si}(111)$, except under special conditions. ${ }^{20}$ Adsorption does occur on $\mathrm{Si}(100)^{18-19}$ and there is evidence for the disruption of the $2 \times 1$ dimer structure. The interaction is extremely weak, as reflected in the low sticking coefficient, as well as the complete molecular desorption near $200 \mathrm{~K}$.

While $\mathrm{CO}$ on $\mathrm{Si}(100)$ has received little attention due to the weak interactions, other $\pi$-bonded systems have attracted much more interest. Ethylene and propylene have been studied by several researchers. ${ }^{21-24}$ These desorb, intact, between 550 and $580 \mathrm{~K}$ with some dissociation-2\%-5\% for monolayer ethylene ${ }^{3}$ and $65 \%$ for monolayer propylene. For ethylene, two models have been proposed for the adsorption geometry, and both depend upon a di- $\sigma$ bonded structure. In

${ }^{a}$ Electronic mail: cmab710@utxsvs.cc.utexas.edu the first, ethylene saturates the dangling bonds of each dimer, leaving the single $\mathrm{Si}-\mathrm{Si}$ bond of the dimer intact, ${ }^{33}$ while the other cleaves the $\sigma$ bond between neighboring silicon atoms, leaving a single unshared electron on each atom. ${ }^{21,22}$ In either case, scanning tunneling microscopy (STM) ${ }^{3}$ has shown that ethylene bonds nondissociatively across the dimer pairs. The STM results also show that ethylene initially adsorbs on alternating dimer pairs along each row, but, upon saturation, there is approximately one ethylene molecule per $\mathrm{Si}-\mathrm{Si}$ unit suggesting that inter-adsorbate interactions strongly influence the initial adsorption.

We report here data for the reaction of acetone and acetaldehyde on $\mathrm{Si}(100)$ over the temperature range of $110-1000$ $\mathrm{K}$. We found several features common to both adsorbates. First, the carbonyl binds to the silicon surface in two states, some by reducing the bond order of the carbonyl, and the remainder by complete dissociation of the carbonyl bond. Second, as each adsorbate decomposes it releases gas phase products-ethylene for acetaldehyde and propylene for acetone. Furthermore, residual alkyl groups undergo decomposition forming silicon carbide and produces $\mathrm{H}_{2}$, while oxygen leaves the surface in the form of $\mathrm{SiO}$. We show that the aliphatic substituents (two methyl groups on acetone and one on acetaldehyde) dehydrogenate via a surface mediated desorption. Experiments on $\mathrm{Si}(100)$, damaged by argon ion sputtering, which disrupts the dimer structure, exhibit less carbonyl dissociation indicating that dimers play a central role in the behavior of the carbonyl adsorption.

\section{EXPERIMENT}

A rectangular sample of $\mathrm{Si}(100), 0.8 \mathrm{~cm} \times 1.7 \mathrm{~cm}$ and 0.2 $\mathrm{cm}$ thick, was cut from a $p$-type $\mathrm{Si}(100)$ wafer with $20-30$ $\Omega \mathrm{cm}$ resistivity. Taking care not to damage the polished surface, the unpolished side of the sample was treated with a dilute solution of HF, followed by sputter depositing $\mathrm{Ta} /$ W/Ta films of thickness 300/2000/300 A. The resistance of 
the film was 10-16 $\Omega$. This preparation method allows for direct resistive heating by first passing current through the metal film until the silicon temperature rises to the point where the Si sample becomes more conductive than the film. This avoids the characteristic sharp drop in resistance exhibited by silicon when the sample reaches a temperature such that carriers are thermally promoted into the conduction band. The change in resistance is sufficiently gradual that a Eurotherm 815 temperature controller maintained a linear ramp throughout the desired temperature range for heating rates of $1-10 \mathrm{~K} / \mathrm{s}$. The deposited film was destroyed upon heating to temperatures greater than $\sim 1500 \mathrm{~K}$.

The sample was wedged between two tantalum clips clamped into a mount which was fixed on the end of a manipulator rod. The sample mount was constructed to provide electrical isolation while maintaining good thermal contact with the liquid nitrogen $\left(\mathrm{LN}_{2}\right)$ heat sink. In this configuration, the sample could be cooled to as low as $100 \mathrm{~K}$ in $\sim 10$ min with an attainable base temperature of $90 \mathrm{~K}$.

The sample/manipulator assembly was placed in an ultrahigh vacuum (UHV) system. The UHV system, described in detail elsewhere, ${ }^{26}$ is equipped with a quadrupole mass spectrometer (QMS) for temperature programmed desorption (TPD) and residual gas analysis, an x-ray source and a hemispherical analyzer for x-ray photoelectron spectroscopy (XPS), an argon ion gun for sputtering, and an LK-2000 high resolution electron energy loss spectrometer (HREELS). The mass spectrometer was differentially pumped by a $30 \mathrm{\ell} / \mathrm{s}$ ion pump. The quadrupole shroud was fitted with an entrance aperture one 1/4 in. in diameter. Finally, atomic hydrogen was dosed by passing $\mathrm{H}_{2}$ gas over a heated tungsten filament protruding into the vacuum chamber. The filament was heated to $2500 \mathrm{~K}$ during dosing with an estimated cracking efficiency of $\sim 1 \%$.

All XPS spectra were collected over three regions: $\mathrm{C}(1 s), \mathrm{O}(1 s)$ and $\mathrm{Si}(2 p)$. The $\mathrm{Si}(2 p)$ was used for a reference to correct for any charging effects as well as to normalize with other data. Spectra were typically recorded using a pass energy of $50 \mathrm{eV}$. The step size and scan window were 0.05 and $20 \mathrm{eV}$, respectively, and fifteen scans were collected for a total scan time of approximately $20 \mathrm{~min}$. For TPD measurements, the sample was positioned approximately $0.8 \mathrm{~cm}$ away from aperture of the mass spectrometer. The QMS filament position with respect to the aperture was such that it prevented line of site to the sample. The current to the sample was less than $0.1 \mu \mathrm{A}$. Nevertheless, spectra were collected shortly after turning on the QMS filament to avoid any effects from spurious electrons. HREELS was performed on both a clean and dosed sample with a beam energy of $5 \mathrm{eV}$. Resolutions, measured by the full width at halfmaximum (FWHM) varied from about $56 \mathrm{~cm}^{-1}(7.0 \mathrm{meV})$ to $140 \mathrm{~cm}^{-1}(\sim 16 \mathrm{meV})$.

The oxide was removed by flashing the sample to $1200 \mathrm{~K}$ for $1 \mathrm{~min}$. Subsequent cleaning of carbon contamination was accomplished by sputtering with argon ions at an energy of $\sim 500 \mathrm{eV}$ and a current of $2.5 \mu \mathrm{A}$ while holding the sample at a temperature of $600-700 \mathrm{~K}$. The sample was then an-

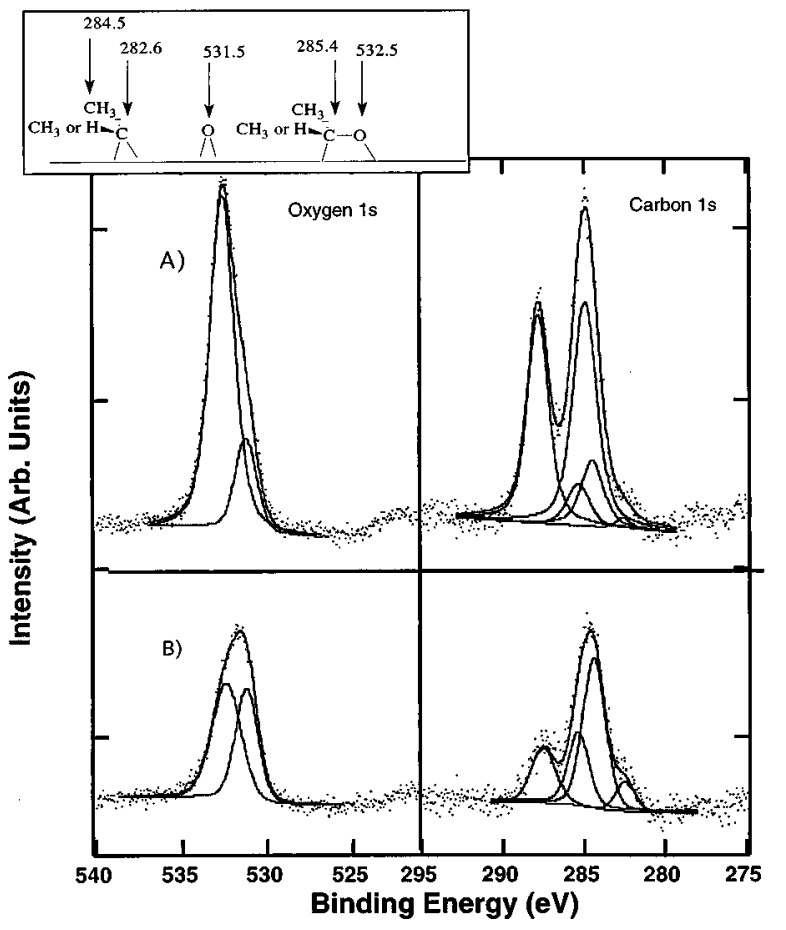

FIG. 1. $\mathrm{C}(1 s)$ and $\mathrm{O}(1 s)$ XPS spectra for $22 \mathrm{~L}$ dose of acetaldehyde on $\mathrm{Si}(100)$ at $T_{\text {dose }}=110 \mathrm{~K}$ : (A) as dosed for the multilayer and (B) flashing to $180 \mathrm{~K}$ for $30 \mathrm{~s}$ leaving only the monolayer.

nealed to $1100 \mathrm{~K}$ for $1 \mathrm{~min}$ and slowly cooled to base temperature. This procedure was repeated until XPS revealed no impurities within the limits of detection $(\sim 1 \%)$. The quality of the surface was periodically checked with hydrogen desorption experiments, providing benchmark data that could be compared with data reported in the literature. ${ }^{27}$

Acetone (Aldrich) was purified by long term exposure to molecular sieves (to remove water). Acetaldehyde (Aldrich) was used without further purification. Each adsorbate underwent several freeze-pump-thaw cycles prior to admission into the vacuum chamber and mass spectral analysis verified purity. Both were dosed through a directed dosing assembly consisting of a calibrated toggle valve connected to a $3 \mathrm{~mm}$ inside diameter (i.d.) stainless steel tube opening into the vacuum chamber. For all the experiments, the sample temperature was reproducibly controlled between 110 and $140 \mathrm{~K}$ during dosing.

\section{RESULTS AND DISCUSSION}

\section{A. Initial adsorption}

Acetone and acetaldehyde adsorb on silicon with similar results. XPS experiments allowed us to observe the initial adsorption state for both the multilayer and monolayer of each adsorbate. A clean $\mathrm{Si}(100)$ surface was dosed with $22 \mathrm{~L}$ of acetone or acetaldehyde with the temperature held at 110 $\mathrm{K}$. The $\mathrm{O}(1 s)$ and $\mathrm{C}(1 s)$ regions are plotted in Figs. 1 and 2 for acetaldehyde and acetone, respectively; the upper traces correspond to the multilayer. The sample was flashed to de- 


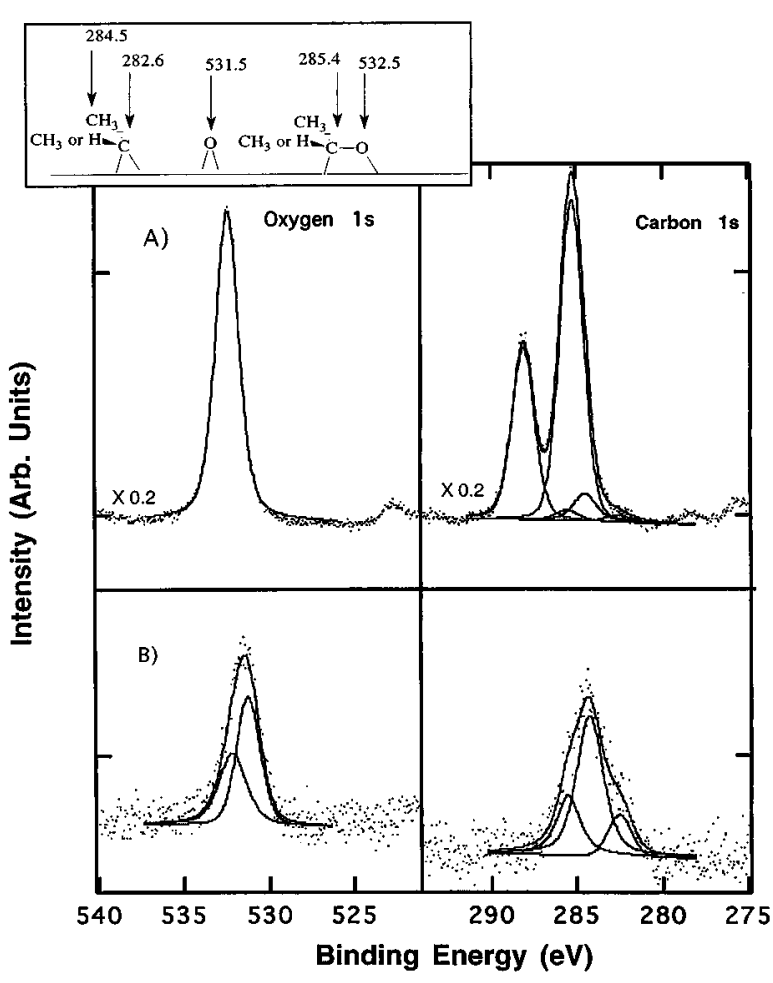

FIG. 2. $\mathrm{C}(1 s)$ and $\mathrm{O}(1 s)$ XPS spectra for $22 \mathrm{~L}$ dose of acetone on $\mathrm{Si}(100)$ at $T_{\text {dose }}=110 \mathrm{~K}$ : (A) as dosed for the multilayer and (B) flashing to $200 \mathrm{~K}$ for 30 leaving only the monolayer.

sorb the multilayer $(180 \mathrm{~K}$ for acetaldehyde and $200 \mathrm{~K}$ for acetone) and the XPS was then reacquired (lower traces in Figs. 1 and 2).

The data we present in Figs. 1 and 2 required deconvolution because the individual states were not readily resolved. For the multilayer, the FWHM for the $\mathrm{O}(1 s)$ peak is $2.1-2.2$ $\mathrm{eV}$ for both acetone and acetaldehyde (upper traces Figs. 1 and 2). Calibration data for our spectrometer indicated the FWHM for a single oxygen state to be $1.7 \mathrm{eV}$. Using $1.7 \mathrm{eV}$ as a criterion for the FWHM, we established the presence of two separate identifiable $\mathrm{O}(1 s)$ peaks and fitted them using XPS fitting software. ${ }^{28}$ Similarly, for $\mathrm{C}(1 s)$ the measured FWHM for a single state was $1.6 \mathrm{eV}$. The $\mathrm{C}(1 s)$ states have FWHM near $2.5 \mathrm{eV}$ for the low binding energy peaks and the required fits are shown in Figs. 1 and 2. Base line corrections utilized the Shirley background method which corrects for the contributions of secondary electron. Using the Shirley fit, the $\mathrm{C} / \mathrm{O}$ total peak area ratio (accounting for sensitivity factors) was, within experimental error, 2.0 for acetaldehyde and 3.0 for acetone.

Referring to the upper traces of Figs. 1 and 2, the $\mathrm{O}(1 s)$ region for acetone and acetaldehyde both have peak binding energies of $532.7 \mathrm{eV}$ representing the multilayer. After we removed the multilayer for acetaldehyde, the $\mathrm{O}(1 s)$ region shows a slight asymmetrry in the peak, again consisting of two different oxygen states of $1.7 \mathrm{eV}$ FWHM: one at 532.4 and the other near $531.5 \mathrm{eV}$. Similarly, acetone yields peak positions at 532.5 and $531.4 \mathrm{eV}$. The existence of two $\mathrm{O}(1 s)$ states suggests two different adsorption structures in the monolayer. These peak shifts may be explained using an argument based on initial state effects. The electron affinity for silicon relative to oxygen (or carbon) is lower; electron density would increase on atoms that bind to silicon. We expect, and indeed observe, peak shifts to lower binding energy for oxygen and carbon as well.

The $\mathrm{C}(1 s)$ region is slightly more complicated. For multilayer acetaldehyde, we observe two distinct peaks in the XPS, one at $287.7 \mathrm{eV}$ and another at $285.2 \mathrm{eV}$, which we assign to the carbonyl and aliphatic carbons, respectively. The intensity ratio is greater than unity and becomes 1.0 only after subtraction of $\mathrm{C}(1 s)$ contributions from the monolayer. Turning to acetone, which accumulates more material $(\sim 25$ ML estimated from XPS peak areas) under our dosing conditions, we identify two $\mathrm{C}(1 s)$ peaks with the same binding energy as acetaldehyde. Comparing these two peaks (287.6 and $285.2 \mathrm{eV}$ ) we measure a ratio of aliphatic carbon to carbonyl carbon to be 2.1; subtracting the contributions from the underlying monolayer gives a 2.0 ratio as expected for acetone.

Turning now to the monolayer spectra (lower panels of Figs. 1 and 2), we deconvolved the raw data to give three distinct peaks for acetone and four for acetaldehyde. The peak at 287.8 for acetaldehyde comes from an acetaldehyde molecule with the carbonyl essentially intact (we shall show later that this contribution disappears near room temperature). The other peaks at 285.4, 284.5, and 282.6 are common to both acetone and acetaldehyde. We assign the 285.4 $\mathrm{eV}$ state to the carbonyl carbon which has been reduced in bond order and has also gained electron density from $\mathrm{Si}$. We attribute the peak at $284.5 \mathrm{eV}$ to aliphatic $-\mathrm{CH}_{3}$ or, possibly, $=\mathrm{CH}_{2}$, while $282.6 \mathrm{eV}$ is assigned to carbon that is bonded strongly to $\mathrm{Si}^{29}$

This data shows that the carbon and oxygen atoms of the carbonyls interact strongly with the silicon surface. To account for two different oxygen states and multiple carbon states, we postulate that one state represents a carbonyl bond that has been reduced in bond order, forming what appears to be a di- $\sigma$ bond through the carbonyl atoms spanning a dimer, similar to that observed for ethylene. This would account for the large shift from 287 to $285.6 \mathrm{eV}$ binding energy for the $\mathrm{C}(1 s)$ since the carbon atom, originally the carbon of the carbonyl, would be bound to a slightly less electronegative atom, silicon, while remaining bonded to the slightly more electronegative oxygen. The other adsorbed species, we propose, represent cleavage of the carbonyl bond forming atomically adsorbed oxygen and molecularly adsorbed alkyl fragments, in this case the carbon and oxygen of the carbonyl would have little influence on each other, accounting for the $282.6 \mathrm{eV}$ carbon. The shift in the carbonyl peak position for the $\mathrm{C}(1 s)$ is the strongest evidence for disruption of the $\mathrm{C}=\mathrm{O}$ bond for either molecule. The shift in peak positions for $\mathrm{O}(1 s)$ is not quite as large and, under our fitting algorithm, we are not able to distinguish easily between the $\mathrm{O}(1 s)$ states in $\mathrm{C}=\mathrm{O}$ and $\mathrm{C}-\mathrm{O}$; however, we do observe two separate $\mathrm{O}(1 s)$ binding energies indicative of severed carbonyl bonds. Overall, according to our model, we expect 


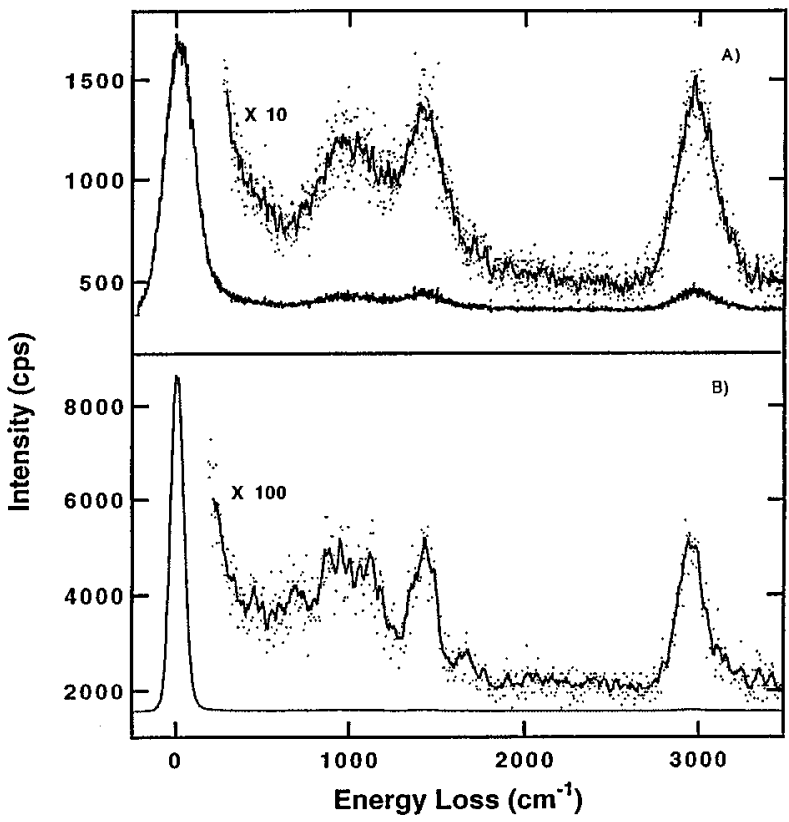

FIG. 3. HREELS spectrum for acetone (upper panel) and acetaldehyde (lower panel). The resolution, by FWHM of the elastic peak taken in the specular direction, is $123 \mathrm{~cm}^{-1}$ for acetone and $65.3 \mathrm{~cm}^{-1}$ for acetaldehyde.

the major contributions in $\mathrm{C}(1 s)$ and $\mathrm{O}(1 s)$ regions for the adsorbed species to give rise to three carbon states and two oxygen states as shown by the inset of Fig. 1 for the XPS peak assignments. If the di- $\sigma$ bonded species do exist, then it is possible this is a precursor which would lead to the observed cleavage of the $\mathrm{C}=\mathrm{O}$ bond. We would expect further bond rupture would occur with increasing temperature.

HREELS provides insight into the condition of the carbonyl bond when acetaldehyde or acetone initially adsorb on the silicon surface. Multilayers caused total loss of signal. Therefore, spectra shown in Fig. 3 are for the monolayer alone. Though the resolution is poorer for the acetone case $\left(\sim 123 \mathrm{~cm}^{-1}\right.$ FWHM), we do observe several features vital to our discussion. Notable is the absence of a strong loss in the $1700-1800 \mathrm{~cm}^{-1}$ range, which would indicate $\mathrm{C}=\mathrm{O}$ (the $\mathrm{C}=\mathrm{O}$ stretching mode). The other assigned features are at $2990 \mathrm{~cm}^{-1}$ for the $\mathrm{C}-\mathrm{H}$ stretching mode and $1443 \mathrm{~cm}^{-1}$ for the $\mathrm{CH}_{3}$ rocking mode. Off specular measurements did not resolve any new features.

In HREELS of acetone on metal surfaces, the $\mathrm{C}=\mathrm{O}$ stretch is typically a strong feature; for example, in the case of acetone adsorbed on $\mathrm{Pt}(111)$, the carbonyl intensity is three times the intensity of the $\mathrm{C}-\mathrm{H}$ stretching modes. ${ }^{30}$ For acetone on a $\mathrm{Pt}$ foil, ${ }^{31}$ the carbonyl stretching was about three quarters of the $\mathrm{C}-\mathrm{H}$ stretching intensity.

We take the absence of the carbonyl features in the HREELS, together with the XPS data, to be strong evidence for partial and/or complete disruption of the carbonyl bond during adsorption. This is to be compared to aliphatics which do not bind readily to silicon and with $\mathrm{CO}$ which requires thousands of Langmuirs (L) exposure before detectable

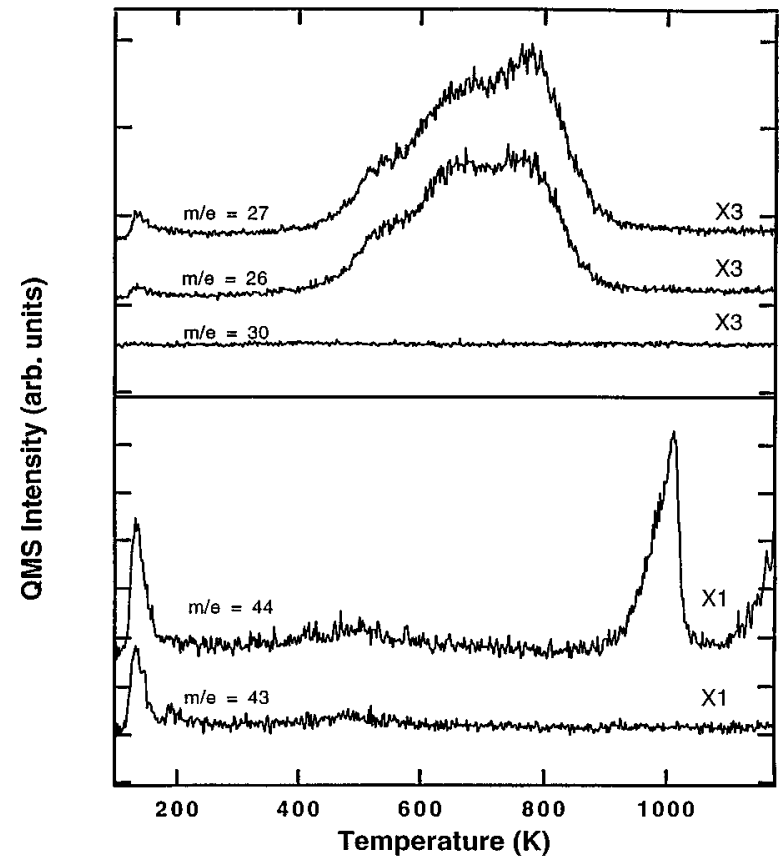

FIG. 4. Temperature programmed desorption experiment for a $22 \mathrm{~L}$ dose of acetaldehyde on $\mathrm{Si}(100)$ at $T_{\text {dose }}=110 \mathrm{~K}$. The heating rate was $4.0 \mathrm{~K} / \mathrm{s}$. The lower panel is scaled three times that of the upper panel.

amounts accumulate. ${ }^{18-20}$ Here, $20 \mathrm{~L}$ doses are more than sufficient to saturate the monolayer.

\section{B. Decomposition}

\section{TPD gas phase desorption products}

The above evidence is strong that the carbonyl bonds side-on through both the carbon and oxygen. We now discuss the products appearing in TPD and companion XPS and HREELS data. The samples were dosed in the same wayroughly $22 \mathrm{~L}$ while holding the temperature at $110 \mathrm{~K}$.

Acetaldehyde results are shown in Fig. 4. Two mass fragments, mass 26 and 27, assigned to ethylene, appear at $550 \mathrm{~K}$ with a sharp drop-off near 770-780 K. We also monitored several masses throughout the experiments, paying particular attention to mass 30 , which would indicate the formation of ethane; there was never a peak in this signal. The lower panel of Fig. 4 shows masses 43 and 44, both attributable to acetaldehyde. The $130 \mathrm{~K}$ peak is assigned to desorption of multilayer acetaldehyde. There is a strong mass 44 peak at $1000 \mathrm{~K}$ which we assign to SiO (supported by XPS discussed later). Finally, there is a small increase in what appears to be acetaldehyde desorption at $460 \mathrm{~K}$. Its origin is not known but may be from nonsample surfaces; it is not discussed further.

For acetone, Fig. 5 shows, for a monolayer dosed at 130 $\mathrm{K}$, strong signals at 27 and $42 \mathrm{amu}$ (upper panel). The ratios are consistent with propylene. The small bump in the trace for mass 27 indicates possible ethylene desorption; however, artifacts from the ion pump, which differentially pumps the quadrupole mass spectrometer, are more likely. The small bump for mass 27 was not consistently reproducible and, in 


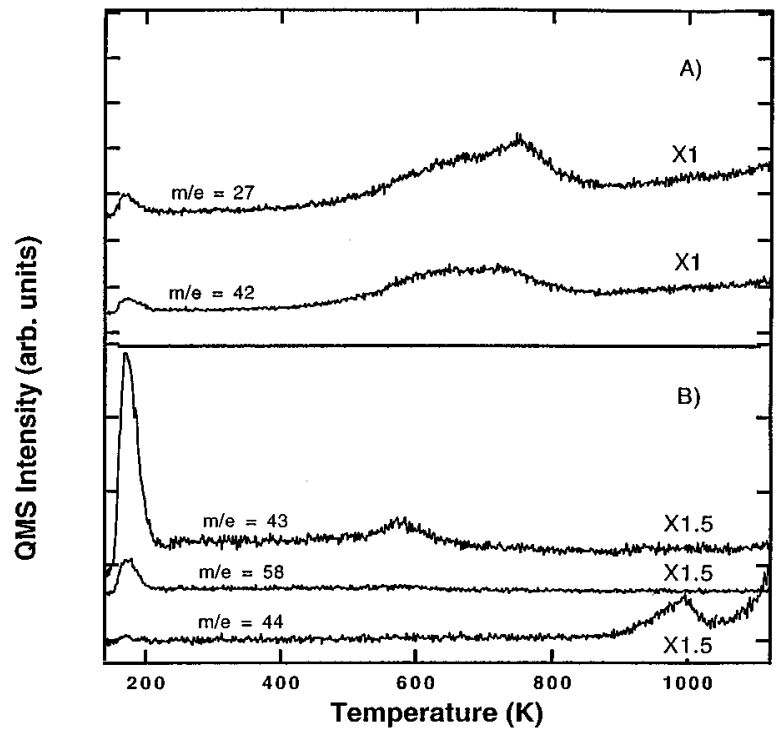

FIG. 5. Temperature programmed desorption experiment for a $22 \mathrm{~L}$ dose of acetone on $\mathrm{Si}(100)$ at $T_{\text {dose }}=130 \mathrm{~K}$. The heating rate was $4.0 \mathrm{~K} / \mathrm{s}$. The lower panel is scaled one and half times that of the upper panel.

our benchmark hydrogen experiments, we observed ethylene as well as other hydrocarbon fragments in the same temperature range. We believe is a memory artifact since small pressure bursts could cause the ion pump to release hydrocarbon fragments.

In the lower panel we observe a molecular desorption peak near $570 \mathrm{~K}$ as well as the molecular desorption peak at $163 \mathrm{~K}$. Previous experiments on this system assigned the 163 $\mathrm{K}$ desorption to a bilayer since, in this experiment, the sample base temperature was not low enough to permit for-

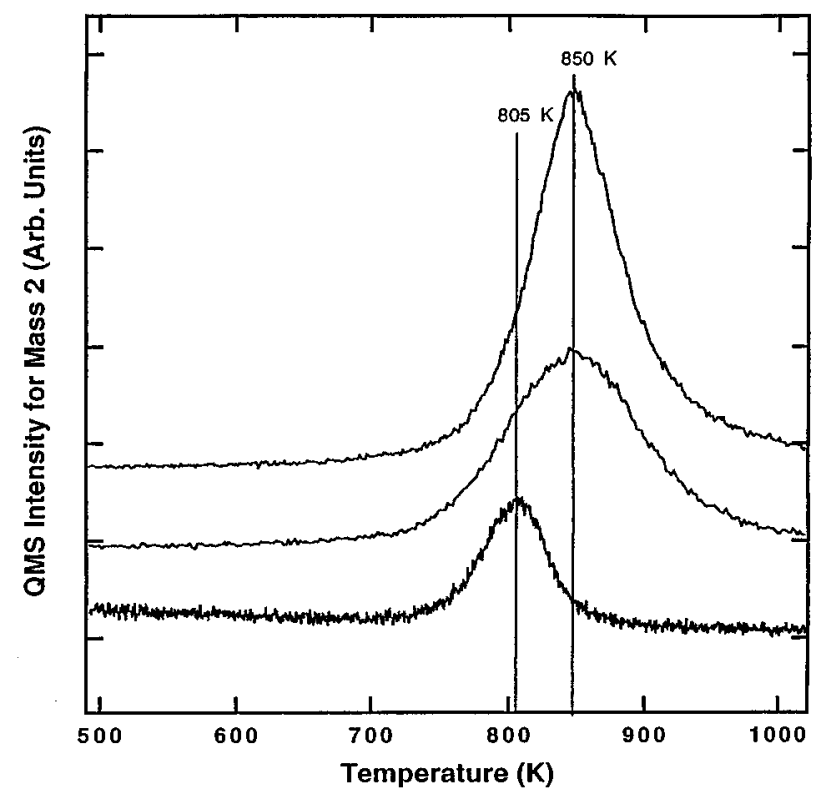

FIG. 6. Hydrogen TPD spectra from (a) acetone dosed (22 L) on $\mathrm{Si}(100)$ at $T_{\text {dose }}=130 \mathrm{~K}$, (b) acetaldehyde dosed $(22 \mathrm{~L})$ on $\operatorname{Si}(100)$ at $T_{\text {dose }}=110 \mathrm{~K}$ and (c) a hydrogen saturated $\operatorname{Si}(100)$ surface $\beta_{1}$ state.

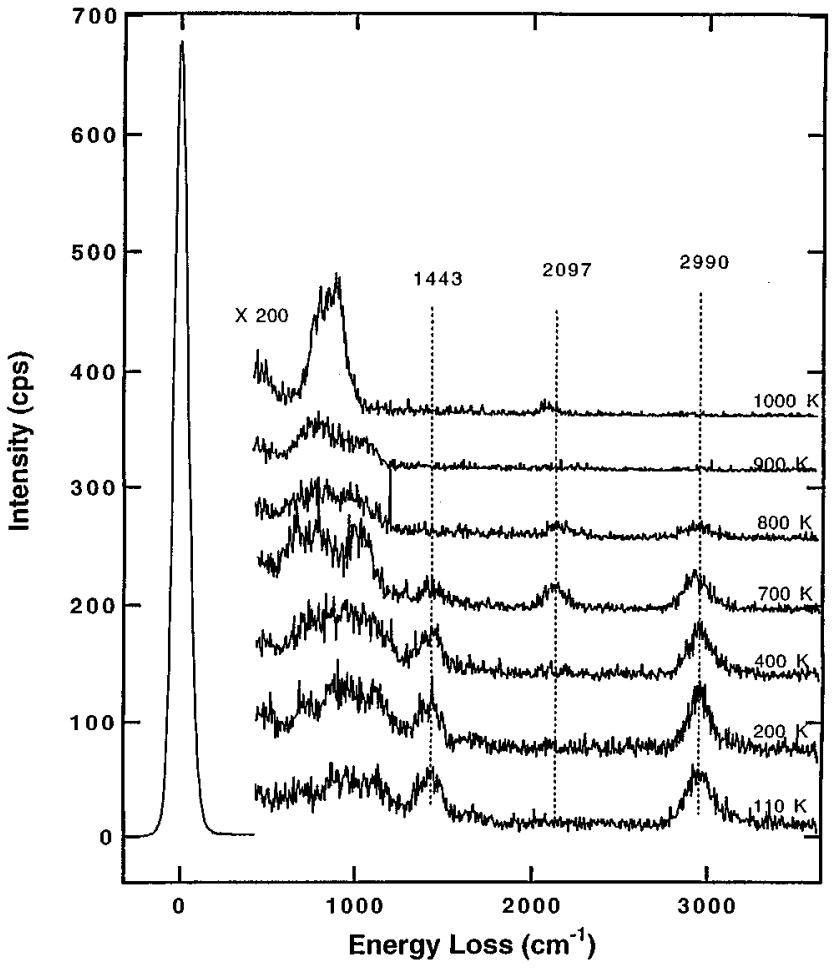

FIG. 7. HREELS anneal series for acetaldehyde (22 L) adsorbed on $\mathrm{Si}(100)$ $T_{\text {dose }}=110 \mathrm{~K}$. Anneal temperatures marked on each curve-110, 200, 400, $700,800,900$, and $1000 \mathrm{~K}$. Each anneal for $1 \mathrm{~min}$ FWHM $72 \mathrm{~cm}^{-1}$. Key assignments: $1443 \mathrm{~cm}^{-1} \mathrm{CH}_{3}$ rocking, $2097 \mathrm{~cm}^{-1} \mathrm{Si}-\mathrm{H}$ stretch and $2990 \mathrm{~cm}^{-1} \mathrm{C}-\mathrm{H}$ stretch.

mation of a multilayer. ${ }^{32}$ Like acetaldehyde, acetone shows a mass 44 desorption feature near $1000 \mathrm{~K}$ which, again, we assign to $\mathrm{SiO}$.

Figure 6 shows the desorption of hydrogen, which is the most intense TPD product for acetone and acetaldehyde. We also show a typical hydrogen desorption trace from a saturated monohydride $\left(\beta_{l}\right)$ hydrogen covered $\mathrm{Si}(100)$ surface. Two points are to be made. First, the total peak area is much greater, in some cases two or three times greater, for hydrogen desorbing from the acetone or acetaldehyde system than for hydrogen desorption from the saturated $\beta_{l}$ feature. Second, each peak is shifted to higher temperature by $40 \mathrm{~K}$. Others have observed similar behavior for hydrogen desorption from aliphatics on $\mathrm{Si}(100) .{ }^{34}$ We suggest here that, near $700 \mathrm{~K}$, dehydrogenation begins by transferring hydrogen from the aliphatic groups to the $\mathrm{Si}(100)$ surface followed by recombinative desorption. Whether or not the methyl groups have migrated directly to the $\mathrm{Si}(100)$ surface prior to dehydrogenation is not clear from our data; however, hydrogen attachment to $\mathrm{Si}$ is evidenced by a definite $\mathrm{Si}-\mathrm{H}$ stretching frequency observed in HREELS between 650 and $750 \mathrm{~K}$.

\section{HREELS results for decomposition}

The gas phase desorption products of ethylene and propylene for acetaldehyde and acetone, respectively, suggest a common reaction pathway. Figure 7 shows an HREELS anneal series for acetaldehyde. In forming ethylene or propy- 

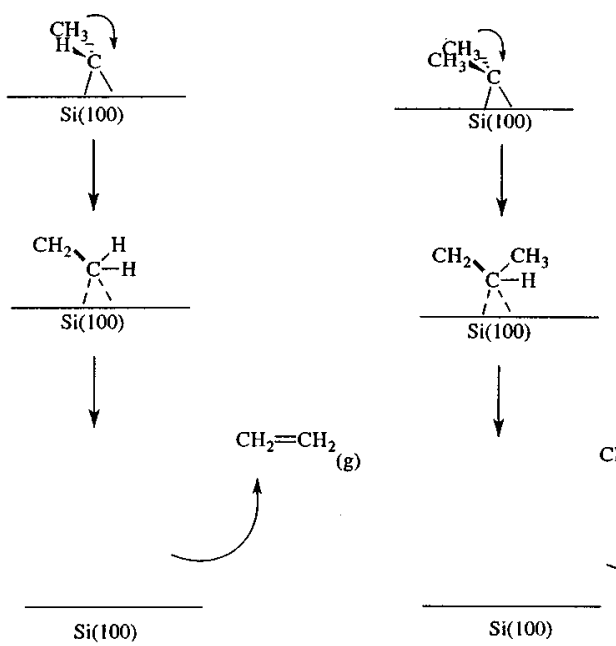

(A)

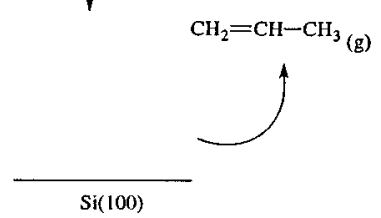

(B)

FIG. 8. Proposed mechanism by which alkyl fragments from (A) acetone and (B) acetaldehyde produce ethylene and propylene, respectively.

lene, where the onset begins near 400-450 K, a hydrogen from one aliphatic carbon must transfer to the carbon of the carbonyl. There are two possibilities: surface mediated hydrogen transfer or intramolecular transfer. The surface mediated mechanism requires dehydrogenation of some aliphatic groups followed by $\mathrm{H}$ diffusion prior to forming and desorbing the olefin. For intramolecular transfer the aliphatic hydrogen transfers in concerted fashion from the aliphatic substituent to the carbonyl carbon. HREELS was used to search for evidence of the first path. The results are plotted in Fig. 7 for acetaldehyde; the same was observed for acetone. The absence of a Si-H stretching vibration $\left(-2100 \mathrm{~cm}^{-1}\right)$ through $600 \mathrm{~K}$ rules out any surface mediated reaction pathway that would allow the accumulation of $\mathrm{Si}-\mathrm{H}$. Furthermore, if the surface diffusion model were operative we would expect to observe other hydrogenation reactions, whereas we were only able to observe propylene (or ethylene in the acetone case) desorbing. We propose that the intramolecular transfer mechanism is operative (Fig. 8), in which the $\beta$-hydrogen shifts to the $\alpha$-carbon, giving an adsorbed ethylene (from acetaldehyde) or propylene (from acetone). Once the transfer has taken place, the sample temperature is high enough to immediately desorb ethylene or propylene as observed.

\section{XPS results surface decomposition product}

Annealing experiments using XPS corroborate the $\mathrm{SiO}$ desorption assignment made from the TPD and provide evidence about the fate of the remaining $\mathrm{C}-\mathrm{O}$ species. The surface was dosed with $2.5 \mathrm{ML}$ of acetaldehyde, heated to a predetermined temperature for $1 \mathrm{~min}$, and then cooled before the XPS spectra for the $\mathrm{C}(1 s), \mathrm{O}(1 s)$, and $\mathrm{Si}(2 p)$ were collected (Figs. 9 and 10). The indicated spectral decompositions were done as described above.

For acetaldehyde (Fig. 9), we observe a binding energy of $532.7 \mathrm{eV}$ for $\mathrm{O}(1 s)$ and two peaks for $\mathrm{C}(1 s): 287.7$ and

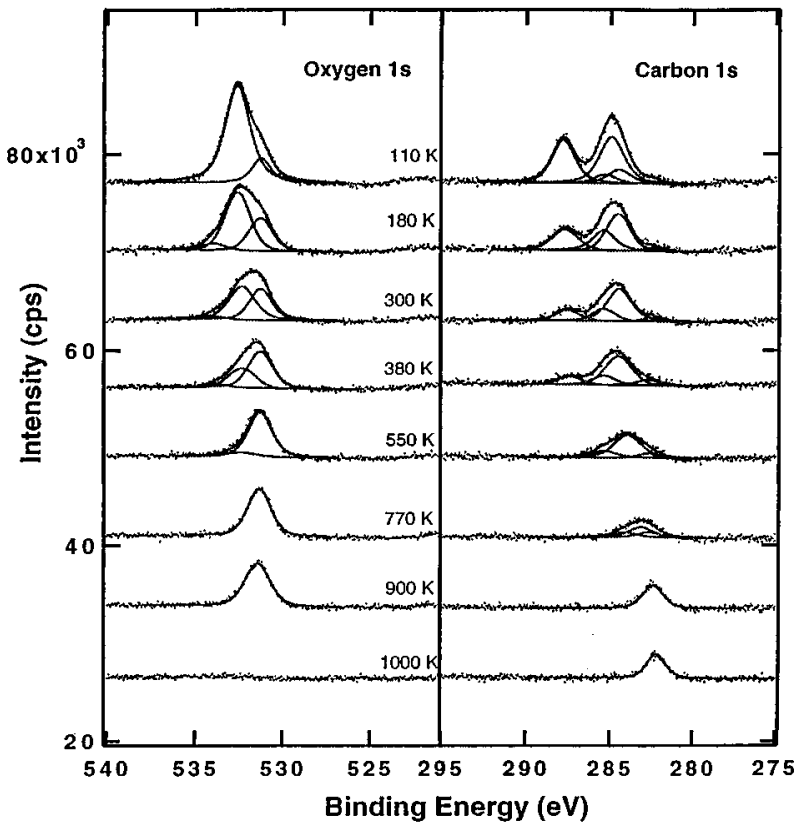

(A)

(B)

FIG. 9. XPS anneal series for $22 \mathrm{~L}$ of acetaldehyde adsorbed on $\mathrm{Si}(100)$ at $110 \mathrm{~K}$. (A) $\mathrm{O}(1 s)$ and (B) $\mathrm{C}(1 s)$ regions annealed from 110, 180, 300, 380, $550,770,900$, and $1000 \mathrm{~K}$.

$285.7 \mathrm{eV}$. Heating the sample to $300 \mathrm{~K}$ (multilayer desorption) leaves two oxygen and four carbon states. The initial $\mathrm{O}(1 s)$ indicates $52 \%$ of the adsorbed molecules are dissociated, as evidenced by the $531.3 \mathrm{eV}$ peak. Heating to $380 \mathrm{~K}$ causes the high binding energy peak to decrease by $53 \%$ while the low binding energy peak increases by approximately $46 \%$. We attribute this to $\mathrm{C}-\mathrm{O}$ bond breaking. After heating to $550 \mathrm{~K}$, the high binding energy peak is negligibly

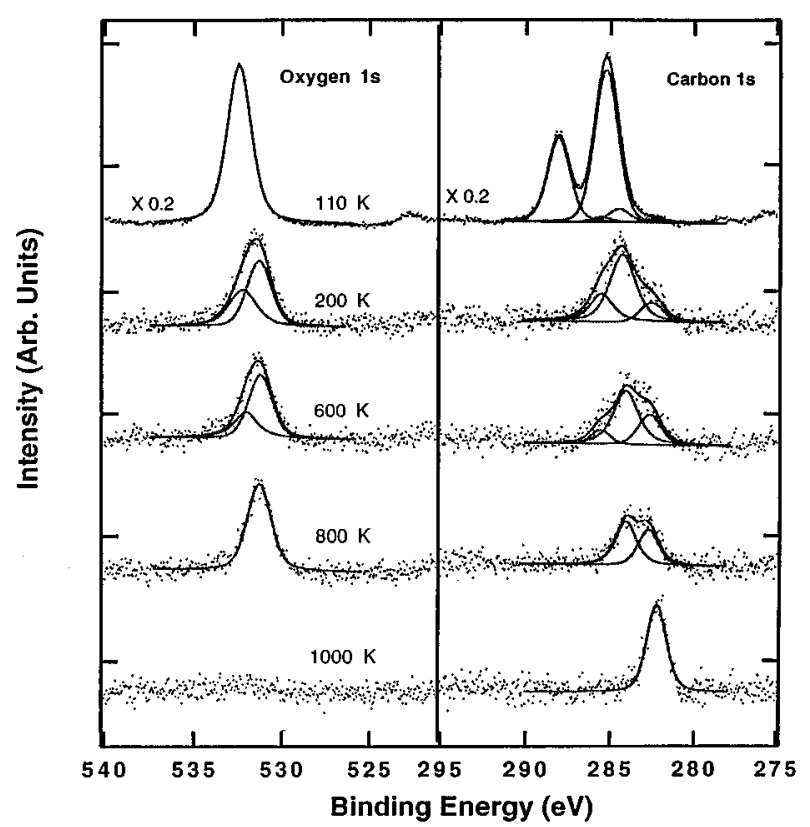

(A)

(B)

FIG. 10. XPS anneal series for $22 \mathrm{~L}$ dose of acetone on $\mathrm{Si}(100)$ at $110 \mathrm{~K}$. (A) $\mathrm{O}(1 s)$ and $(\mathrm{B}) \mathrm{C}(1 s)$ regions annealed from 110, 200,600, 800, and $1000 \mathrm{~K}$. 

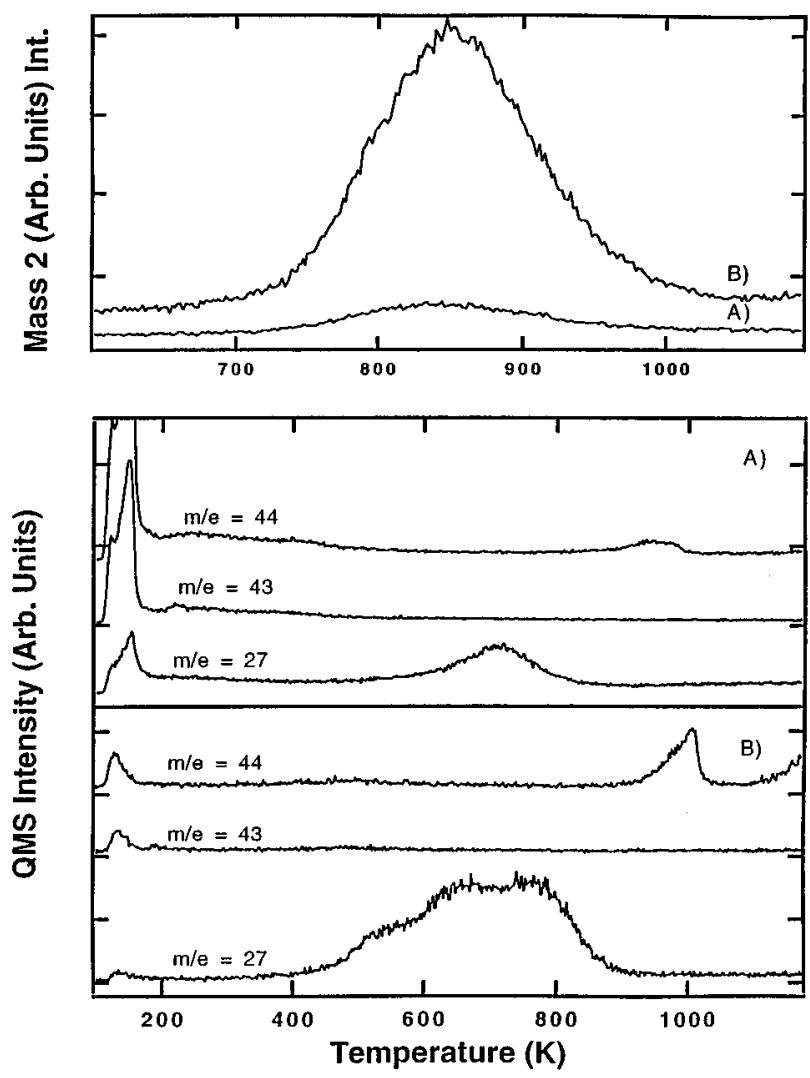

FIG. 11. TPD of acetaldehyde on sputtered and annealed $\mathrm{Si}(100)$. Top plot shows $\mathrm{H}_{2}$ desorption for both the (A) sputtered and (B) annealed $\mathrm{Si}(100)$, lower plot showing mass 44,43 , and 27 amu desorption traces for (A) sputtered and (B) annealed $\mathrm{Si}(100)$. Heating rate as $4 \mathrm{~K} / \mathrm{s}$.

small, while the low binding energy peak $(531.3 \mathrm{eV})$ remains fixed. The total $\mathrm{C}(1 s)$ peak area changes by less than $10 \%$ in heating from 550 to $900 \mathrm{~K}$. In going from 380 to $550 \mathrm{~K}$ the $\mathrm{C} / \mathrm{O}$ ratio changes from 2.05 to 1.65 . For acetaldehyde, this temperature regime overlaps with the temperature region where we observe the ethylene desorption. In going to 770 $\mathrm{K}$, well into the ethylene desorption region, the $\mathrm{C} / \mathrm{O}$ ratio changes from 1.65 to 1.21 . Finally, at $900 \mathrm{~K}$, the total $\mathrm{C}(1 s)$ shifts $\sim 0.4-282.2 \mathrm{eV}$, attributed to silicon carbide, and remains fixed in total area up to $1000 \mathrm{~K}$. The oxygen peak, on the other hand, disappears completely in passing from 900 to $1000 \mathrm{~K}$, supporting the assignment of $\mathrm{SiO}$ desorption in the TPD experiments. Comparing the total $\mathrm{C}(1 s)$ in the silicon carbide, we find that approximately $34 \%$ of the monolayer decomposes to give silicon carbide.

Acetone exhibits similar behavior. Prior to annealing, there are two distinct states for oxygen, and we calculate that $\sim 62 \%$ of the monolayer dissociates upon adsorption. Heating to $600 \mathrm{~K}$, as with acetaldehyde, gives less oxygen in the $532.5 \mathrm{eV}$ state. Above $600 \mathrm{~K}$, on the leading edge of propylene desorption, the total $\mathrm{C} / \mathrm{O}$ ratio is 2.3 . Heating further gives one $\mathrm{O}(1 s)$ peak at $531.4 \mathrm{eV}$, and the high binding energy peak of the $\mathrm{C}(1 s)$ disappears completely, with a total surface $\mathrm{C} / \mathrm{O}$ of 1.8. Finally, as with acetaldehyde, heating to $1000 \mathrm{~K}$ rids the surface of oxygen and leaves a carbon peak centered at $282.2 \mathrm{eV}$.
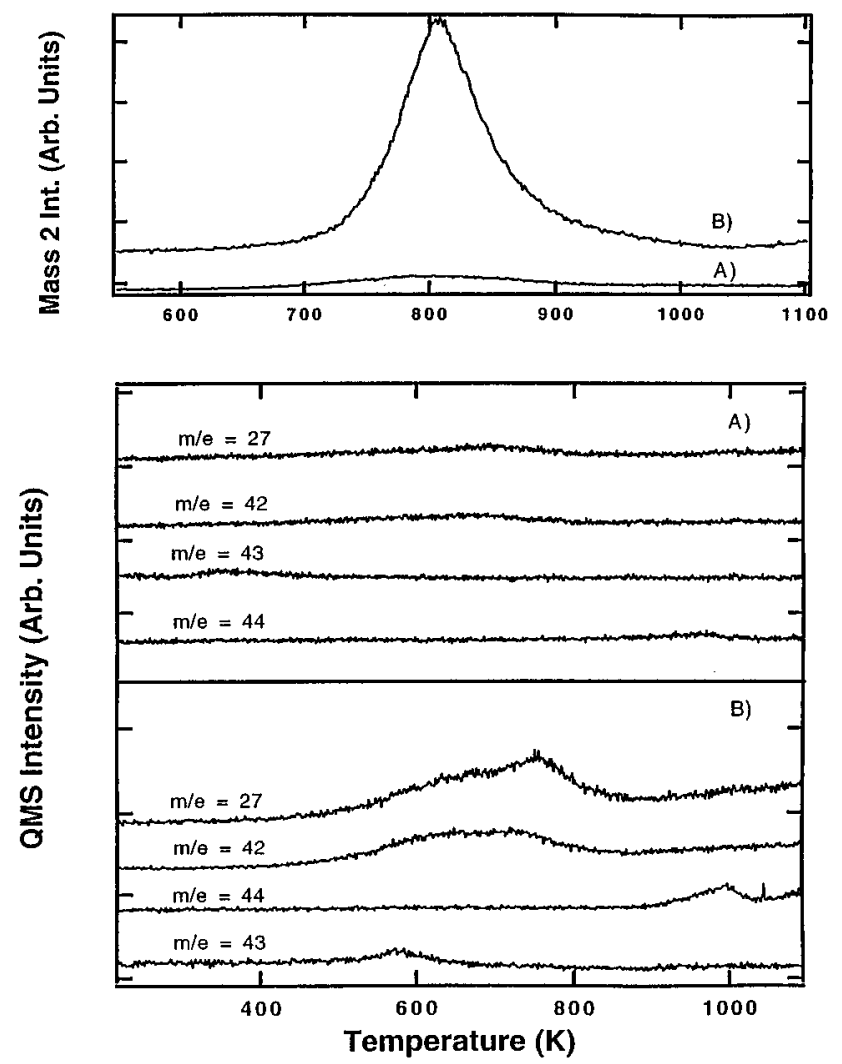

FIG. 12. TPD of acetone on sputtered and annealed $\mathrm{Si}(100)$. Top plot shows $\mathrm{H}_{2}$ desorption for both the (A) sputtered and (B) annealed $\mathrm{Si}(100)$, lower plot showing mass 44, 43, 42, and 27 amu desorption traces for (A) sputtered and $(\mathrm{B})$ annealed $\mathrm{Si}(100)$. Heating rate as $4 \mathrm{~K} / \mathrm{s}$.

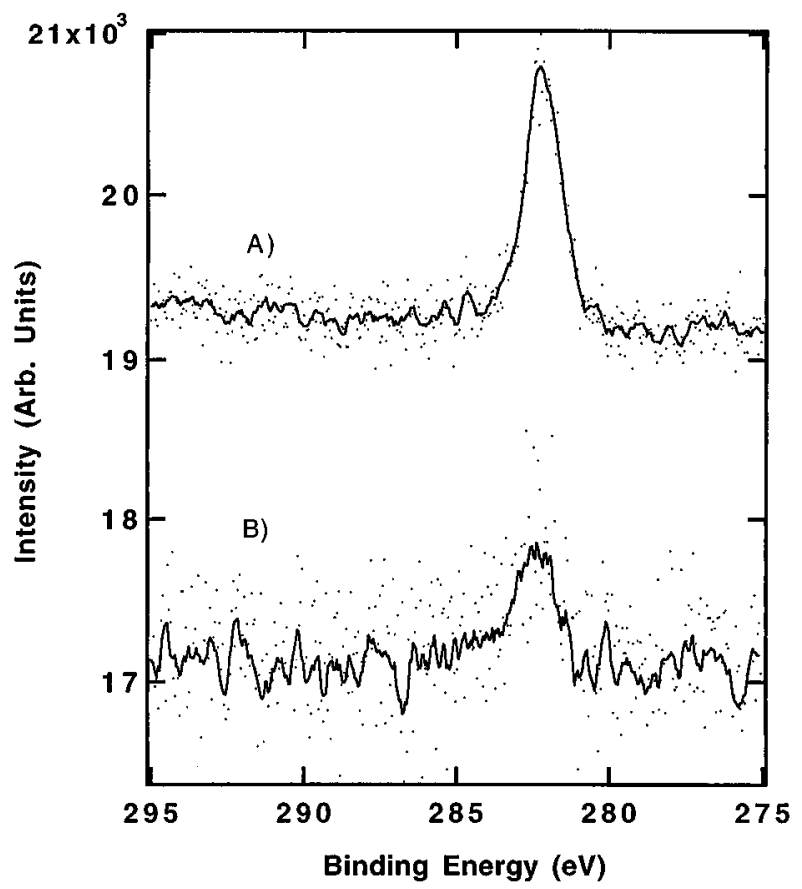

FIG. 13. XPS spectra for the $\mathrm{Si}(100)$ surface dosed with (A) $22 \mathrm{~L}$ on an annealed surface followed by heating to $1000 \mathrm{~K}$ and (B) $60 \mathrm{~L}$ on a sputtered surface followed by heating to $1000 \mathrm{~K}$. 
For both acetone and acetaldehyde, the decreased $\mathrm{C} / \mathrm{O}$ ratio corresponds to the observed desorption of ethylene and propylene species. Others report that less than 5\% of adsorbed ethylene decomposes on a $\mathrm{Si}(100)$ surface. Yates and co-workers show that propylene decomposes to give much more surface carbon $(65 \%){ }^{22}$ These two facts may explain why acetone leaves more carbon behind as compared to acetaldehyde. Finally, the rapid decrease in $\mathrm{O}(1 s)$ signal near $1000 \mathrm{~K}$ for both adsorbates on $\mathrm{Si}(100)$ supports our $\mathrm{SiO}$ desorption assignment and confirms significant carbonyl dissociation.

\section{Sputtered surfaces}

To qualitatively assess the role of surface structure dimers, we performed TPD and XPS on a sputtered Si(100) surface. The surface was first cooled to the dosing temperature then bombarded with $500 \mathrm{eV}$ Ar ions for $15 \mathrm{~min}$. The current was held at $2.5 \mu \mathrm{A}$. Ion energies of this type are known to damage the $\mathrm{Si}(100)$ surface extensively, creating numerous step edges and defects. ${ }^{34}$ After roughening the surface, acetone and acetaldehyde were dosed with approximately three times $(60 \mathrm{~L})$ the dose normally needed to form the multilayer.

The TPD results for acetaldehyde are shown in Fig. 11. In this case, only mass 44, 43, 27, and 2 are plotted. On the sputtered surface, significantly less ethylene desorbs, with a peak desorption temperature of $620 \mathrm{~K}$. Most notable are the decreased $\mathrm{H}_{2}$ and $\mathrm{SiO}$ signals compared to the desorption from the smoother annealed surface. This suggests a decreased reactivity when dimers are partially destroyed.

For acetone (Fig. 12), we observe the same kind of be- havior, a small amount of mass 42 and mass 27 rise above the base line in the sputtered experiment relative to the desorption traces shown for a smoother annealed surface. Furthermore, we observe a dramatic decrease in the SiO desorption channel as well as the hydrogen desorption.

XPS was used to confirm how the reaction products are affected on a sputtered surface. XPS after dosing $60 \mathrm{~L}$ of acetone or acetaldehyde and after annealing to $1000 \mathrm{~K}$ reveal residual carbon (Fig. 13) and no oxygen. The residual carbon is much less than for the same reactions on smoother surfaces, i.e., $14 \%$ of an equivalent monolayer for acetaldehyde and $24.9 \%$ for acetone.

The decrease in signal both in the gas phase products observed in the TPD and the XPS peak intensities suggests that the structure of the $\mathrm{Si}(100)$ strongly influences the chemistry. For a roughened surface, the concentration of dimer bonds is much lower than for the annealed smoother surface. Since our model depends on the dimer structure, intrinsic to smooth $\mathrm{Si}(100)$, we expected that the reaction would be different. The XPS and TPD data support our claim that acetone and acetaldehyde decompose via strong interactions through the carbonyl with the $\mathrm{Si}(100)$ dimers.

\section{CONCLUSIONS}

We observe the facile chemisorption of acetone and acetaldehyde on $\mathrm{Si}(100)$. The XPS and HREELS data both support an initial attack through carbonyl $\pi$ bond resulting in part di- $\sigma$ bonded species and part total dissociative adsorption of the carbonyl. These processes depend on the presence of dimers.

We summarize the reaction schemes below:

For acetaldehyde:

$$
\begin{array}{ll}
\mathrm{CH}_{3} \mathrm{HCO}_{(g)} \rightarrow \mathrm{CH}_{3} \mathrm{HC}-\mathrm{O}_{(a)}+\mathrm{CH}_{3} \mathrm{HC}={ }_{(a)}+\mathrm{O}_{(a)} & 110 \mathrm{~K} \\
\mathrm{CH}_{3} \mathrm{HC}-\mathrm{O}_{(a)}+\mathrm{O}_{(a)} \rightarrow \mathrm{CH}_{3} \mathrm{HC}={ }_{(a)}+\mathrm{O}_{(a)} & 200-600 \mathrm{~K} \\
\mathrm{CH}_{3} \mathrm{HC}={ }_{(a)}+\mathrm{O}_{(a)} \rightarrow \mathrm{CH}_{2} \mathrm{CH}_{2(g)}+\mathrm{CH}_{x(a)}+\mathrm{H}_{(a)}+\mathrm{O}_{(a)} & 500-750 \mathrm{~K} \\
\mathrm{CH}_{x(a)}+\mathrm{H}_{(a)} \rightarrow \mathrm{SiC}_{(a)}+\mathrm{H}_{2(g)}+\mathrm{O}_{(a)} & 850 \mathrm{~K} \\
\mathrm{SiC}_{(a)}+\mathrm{SiO}_{(a)} \rightarrow \mathrm{SiC}_{(a)}+\mathrm{SiO}_{(g)} & 1000 \mathrm{~K}
\end{array}
$$

For acetone:

$$
\begin{array}{ll}
\left(\mathrm{CH}_{3}\right)_{2} \mathrm{CO}_{(g)} \rightarrow\left(\mathrm{CH}_{3}\right)_{2} \mathrm{C}-\mathrm{O}_{(a)}+\left(\mathrm{CH}_{3}\right)_{2} \mathrm{C}={ }_{(a)}+\mathrm{O}_{(a)} & 110 \mathrm{~K} \\
\left(\mathrm{CH}_{3}\right)_{2} \mathrm{HC}-\mathrm{O}_{(a)} \rightarrow\left(\mathrm{CH}_{3}\right)_{2} \mathrm{C}={ }_{(a)}+\mathrm{O}_{(a)} & 200-650 \mathrm{~K} \\
\left(\mathrm{CH}_{3}\right)_{2} \mathrm{C}={ }_{(a)} \rightarrow \mathrm{CH}_{2}=\mathrm{CHCH}_{3(g)}+\mathrm{CH}_{x(a)}+\mathrm{H}_{(a)}+\mathrm{O}_{(a)} & 500-750 \mathrm{~K} \\
\mathrm{CH}_{x(a)}+\mathrm{H}_{(a)} \rightarrow \mathrm{SiC}_{(a)}+\mathrm{H}_{2(g)}+\mathrm{SiO}_{(a)} & 850 \mathrm{~K} \\
\mathrm{SiC}_{(a)}+\mathrm{SiO}_{(a)} \rightarrow \mathrm{SiC}_{(a)}+\mathrm{SiO}_{(g)} & 1000 \mathrm{~K}
\end{array}
$$

Though initial adsorption results in some $\mathrm{C}=\mathrm{O}$ cleavage, silicon continues to actively cleave $\mathrm{C}-\mathrm{O}$ through the temperature range to about $600 \mathrm{~K}$. Acetone leads to propylene desorption and acetaldehyde to ethylene in the same tem- perature regime. We propose a reaction mechanism where one hydrogen shifts from the $\beta$-carbon to the $\alpha$-carbon. When the temperature becomes high enough to decompose $\mathrm{C}-\mathrm{H}$ bonds from residual aliphatics, the ethylene and propy- 
lene desorption cuts off abruptly and a large $\mathrm{H}_{2}$ peak desorbs. The oxygen remaining ultimately desorbs in the form of $\mathrm{SiO}$ as shown by TPD and HREELS. Finally, carbon is retained in the form of $\mathrm{SiC}$.

\section{ACKNOWLEDGMENTS}

J.L.A. would like to thank Noel Russell and Guenter Hess for helpful suggestions and John Ekerdt for the use of his equipment. This work is supported by the Motorola Partnership in Research Program and the National Science Foundation, Science, and Technology Center for the Synthesis, Growth, and Analysis of Electronic Materials, Grant No. CH8920120.

\footnotetext{
${ }^{1}$ Kusunoki and Y. Igari, Appl. Surf. Sci. 59, 95 (1992).

${ }^{2}$ K. P. Loh, C. R. Kingsley, J. S. Foord, and R. B. Jackman, Surf. Sci. 341, 92 (1995).

${ }^{3}$ A. J. Mayne, A. R. Avery, J. Knall, T. S. Jones, G. A. D. Briggs, and W. H. Weinberg, Surf. Sci. 289, 247 (1993).

${ }^{4}$ H. Gutleben, S. R. Lucas, C. C. Cheng, W. J. Choyke, and J. T. Yates, Surf. Sci. 257, 146 (1991).

${ }^{5}$ I. Kusunoki, M. Sakashita, T. Takaoka, and H. Range, Surf. Sci. 357/358, 693 (1996).

${ }^{6}$ P. Doppelt and T. H. Baum, MRS Bull. 19, 41 (1994).

${ }^{7}$ A. V. Gelatos, A. Jain, R. Marsh, and C. J. Mogab, MRS Bull. 19, 49 (1994).

${ }^{8}$ A. Jain, K.-M. Chi, T. T. Kodas, M. J. Hampden-Smith, J. D. Farr, and M. F. Paffett, Chem. Mater. 3, 995 (1991).

${ }^{9}$ D. Temple and A. Reisman, J. Electrochem. Soc. 136, 3525 (1989).

${ }^{10}$ D. H. Kim, R. H. Wentof, and W. N. Gill, J. Electrochem. Soc. 140, 3267 (1993).

${ }^{11}$ D. H. Kim, R. H. Wentof, and W. N. Gill, J. Vac. Sci. Technol. A 12, 153 (1994).
}

${ }^{12}$ W. G. Lai, Y. Xie, and G. L. Griffin, J. Electrochem. Soc. 138, 3499 (1991).

${ }^{13}$ S. L. Cohen, M. Liehr, and S. Kasi, Appl. Phys. Lett. 60, 50 (1992).

${ }^{14}$ G. S. Girolami, P. M. Jeffries, and L. H. Dubois, J. Am. Chem. Soc. 115, 1015 (1993).

${ }^{15}$ G. Nuesca, J. Prasad, and J. A. Kelber, Appl. Surf. Sci. 81, 237 (1994).

${ }^{16}$ R. J. Hamers, R. M. Tromp, and J. E. Demuth, Phys. Rev. Lett. 59, 2071 (1987).

${ }^{17}$ R. J. Hamers, R. M. Tromp, and J. E. Demuth, Surf. Sci. 181, 346 (1987).

${ }^{18}$ Y. Bu and M. C. Lin, Surf. Sci. 298, 94 (1993).

${ }^{19}$ J. P. Chamberlin, J. L. Clemons, A. J. Pounds, and H. P. Gillis, Surf. Sci. 301, 105 (1994).

${ }^{20}$ H. F. Dylla, J. G. King, and M. J. Cardillo, Surf. Sci. 74, 141 (1978).

${ }^{21}$ C. Huang, W. Widdra, and W. H. Weinberg, Surf. Sci. 315, L953 (1994).

${ }^{22}$ (a) M. J. Bozack, P. A. Taylor, W. J. Choyke, and J. T. Yates, Surf. Sci. 179, 132 (1987). (b) L. Clemen, R. M. Wallace, P. A. Taylor, M. J. Dresser, W. J. Choyke, W. H. Weinberg, and J. T. Yates, ibid. 268, 205 (1992).

${ }^{23}$ C. C. Cheng, W. J. Choyke, and J. T. Yates, Surf. Sci. 231, 289 (1990).

${ }^{24}$ M. J. Bozack, P. A. Taylor, W. J. Choyke, and J. T. Yates, Surf. Sci. 177, L933 (1986).

${ }^{25}$ J. Yoshinobu, H. Tsuda, M. Onchi, and M. Nishijima, J. Chem. Phys. 87, 7332 (1987).

${ }^{26}$ B. K. Kellerman, A. Mahajan, N. M. Russell, J. G. Ekerdt, S. K. Banerjee, A. F. Tash, A. Campion, J. M. White, and D. J. Bonser, J. Vac. Sci. Technol. A 13, 1819 (1995).

${ }^{27}$ M. C. Flowers, N. B. H. Jonathan, Y. Lui, and A. Morris, J. Chem. Phys. 99, 7038 (1993).

${ }^{28}$ XPS peak-fitting program: "ISTFIT,"' by C. Truong.

${ }^{29}$ Y. Bu, D. W. Shin, and M. C. Lin, Surf. Sci. 276, 184 (1992).

${ }^{30}$ N. R. Avery, Surf. Sci. 125, 771 (1983).

${ }^{31}$ Z. M. Liu and M. A. Vannice, Surf. Sci. 316, 337 (1994).

${ }^{32}$ M. Langell, J. L. Armstrong, and J. M. White (unpublished).

${ }^{33}$ C. R. Flores, X.-L. Zho, and J. M. White, Surf. Sci. 261, 99 (1992).

${ }^{34}$ P. Bedrossian, Surf. Sci. 301, 223 (1994). 